\title{
Lung Ultrasound: Role and Efficacy in Diagnosing and Follow-up of Patients with Neonatal Respiratory Distress Syndrome
}

\author{
ASMAA M. ABD EL-MAGIED, M.D.* and YASMEEN A. MANSI, M.D.** \\ The Departments of Radiodiagnosis* and Pediatrics**, Faculty of Medicine, Cairo University
}

\begin{abstract}
Background: Neonatal Respiratory Distress Syndrome (NRDS) or hyaline membrane disease result from surfactant deficiency with subsequent alveolar instability and collapse impeding the normal gas exchange. NRDS diagnosis is based primary on clinical findings, laboratory tests and chest radiography. Early diagnosis is crucial to start respiratory support and surfactant replacement.
\end{abstract}

Aim of Work: Evaluate the efficacy of Lung Ultrasound (LUS) in the diagnosis and follow-up of Neonatal Respiratory Distress Syndrome (NRDS) in the premature neonates.

Patients and Methods: Evaluation of 68 preterm neonates presented with respiratory distress and admitted in Neonatal Intensive Care Unit (NICU) was done. The gestational age ranged from 26 to 35 weeks (mean=30.24). The birth weight ranged from $800 \mathrm{gm}$ to $2.950 \mathrm{~kg}$ (mean $=1.429 \mathrm{~kg}$ ). Forty-one patients $(60.3 \%)$ were males and $27(39.7 \%)$ were females. All patients were subjected portable Chest X-Ray (CXR) within few hours of admission followed by bedside lung Bmode ultrasound within 24 hours. Follow-up CXR and ultrasound were done on the 5 th day to monitor response to treatment.

Results: Lung ultrasound was able to diagnose RDS in $68 / 68$ patients on the first day. In comparison with the CXR, LUS had sensitivity, specificity, PPV and NPV of $100 \%$ in diagnosing RDS. On $5 \mathrm{t}^{\mathrm{h}}$ day follow-up, LUS in comparison to CXR as regard detection of persistence or clearance of RDS had both specificity and PPV of $100 \%$ while sensitivity and NPV were $90 \%$ and $90.2 \%$ respectively.

Conclusion: LUS is safe and non-invasive technique and can be used as diagnostic tool in the diagnosis of RDS and following-up the effect of treatment thus reducing number of carried out X-ray.

Key Words: Lung ultrasound - Chest radiography - Neonatal respiratory distress syndrome.

Correspondence to: Dr. Asmaa M. Abd El-Magied, The Departments of Radiodiagnosis, Faculty of Medicine, Cairo University

\section{Introduction}

NEONATAL Respiratory Distress Syndrome (NRDS) or hyaline membrane disease result from surfactant deficiency with subsequent alveolar instability and collapse impeding the normal gas exchange. NRDS is among the commonest causes for admission to the Neonatal Intensive Care Unit (NICU) and one of the leading causes of morbidity in preterm neonates $[1,2]$. NRDS diagnosis is based primary on clinical findings, laboratory tests and chest radiography [1-3]. Early diagnosis is crucial to start respiratory support and surfactant replacement [2]

Chest radiography has been considered to be the standard technique for diagnosing NRDS, and the four-stage scale of RDS severity based on radiographic findings correlates closely with the actual disease severity [4]. Chest X-ray expose the neonates to ionizing radiation and its latent side effects. Follow-up imaging is conducted to monitor the effect of therapy and detect complications if any [2].

Recently, Lung Ultrasound (LUS) has emerged as a diagnostic tool in the evaluation of many neonatal diseases including RDS. Lack of contraindications for ultrasound examination with no radiation risk, low cost, done bedside and easy to perform at NICU have contributed a lot to the clinical and diagnostic utility of the method [5,6].

Ultrasound of normal lung produces horizontal artifacts obscuring the view [2]. In NRDS, the sonographic diagnosis depends upon absence of these horizontal artifacts [7]. 


\section{Patients and Methods}

The study was carried out on 68 preterm neonates. The study was carried out in the Kasr ElAini NICU between April 2015 and May 2016 and it was approved by the Ethics Committee and the institutional review board. The study included 68 preterm neonates $<36$ weeks delivered at Kasr ElAini Hospitals and admitted in NICU during the 1 st 24 hours presenting with respiratory distress and typical CXR abnormalities characteristic of RDS. The gestational age ranged from 26 to 35 weeks (mean=30.24). The birth weight ranged from $800 \mathrm{gm}$ to $2.950 \mathrm{~kg}$ (mean $=1.429 \mathrm{~kg}$ ). $41 / 68$ patients were males $(60.3 \%)$ and $27 / 68$ were females (39.7\%). 23/68 (33.8\%) were delivered vaginally while $45 / 68(66.2 \%)$ were delivered by cesarean section.

\section{Exclusion criteria:}

- Preterm admitted in NICU for other cause than respiratory distress e.g congenital anomalies, neonatal sepsis and birth trauma.

- Preterm neonates suffering from respiratory distress after 24 hours of life.

- Neonates died from neonatal sepsis during the 5 days follow-up.

All patients were subjected to portable CXR within few hours of admission followed by bedside lung ultrasound within 24 hours. Follow-up CXR and ultrasound were done on the $5^{\text {th }}$ day to monitor response to treatment.

Lung ultrasound was performed using Toshiba Alpio ultrasound machine where transthoracic approach in supine positions of the anterior (between the sternum and the anterior axillary line) lung areas in craniocaudal direction was done for all patients using high resolution linear probe (7.5 $\mathrm{MHz}$ ). Intercostal approach from lateral axillary and posterior axillary lines for posterior lung area was done.

\section{Image analysis:}

Portable chest X-ray is done in anteroposterior view. X-ray findings were classified according to severity into 4 stages [8]. Table (1).

Ultrasound examination was performed by qualified radiologist:

With B-mode ultrasound normal lung demonstrates the lung sliding sign and A-Lines. The lung sliding sign; the pleura appears as a smooth, horizontal echogenic moving line between the rib shadows (representing, the sliding of the visceral over the parietal pleura) [9]. A-lines; are horizontal artifacts appearing as parallel echogenic lines below the pleural line [10,11]. Fig. (1).

By ultrasound; the lung was assessed for the following according to Lichtenstein and Mauriat [12] : 1) Absence of A-lines, 2) Pleural line abnormalities, 3) Bilateral compact B-lines Fig. (2) and 4) Sub-pleural consolidation.

Thus, NRDS is classified into: Mild; when the 1 st three signs are present, while severe NRDS is diagnosed when sub-pleural consolidation is found in addition to the three signs.

B-lines: These are vertical 'comet-tail' artifacts extending from pleural line down through whole screen. They appear as hyperechogenic, well defined lines erasing A lines [13]. Fig. (3) B-lines may coalesce producing homogenous echogenic shadow (white lung image).

The whole LUS examinations took approximately 4-5 minutes. Ultrasound gel was kept warm before the examinations to avoid neonate thermal loss.

Follow-up CXR and LUS were done on the 5 th day to monitor response to treatment.

LUS findings were compared with CXR graphic findings as standard radiological examination.

Pleural line thickening and irregularities are the most common ultrasound observations in RDS patients [15]. Lung consolidation can be encountered in RDS patients with the extent of the consolidation varies with the grade of RDS [15]

\section{Statistics:}

Data were statistically described in terms of mean, range and percentages when appropriate. Accuracy was represented using the terms sensitivity, specificity, positive predictive value and negative predictive value.

Table (1): Plain radiography staging of RDS.

\begin{tabular}{ll}
$\begin{array}{l}\text { Radiographic } \\
\text { stage of RDS }\end{array}$ & \multicolumn{1}{c}{ Chest X-ray findings } \\
\hline Stage I & Fine homogenous ground glass shadowing \\
Stage II & Bilateral widespread air bronchogram \\
Stage III & Confluent alveolar shadowing \\
Stage IV & Alveolar shadowing obscuring cardiac border
\end{tabular}




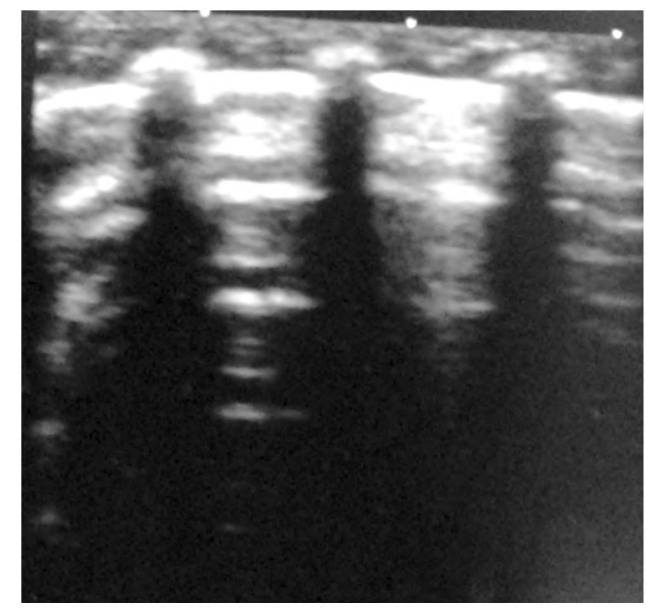

Fig. (1): Normal lung pattern. Longitudinal scan showing the ribs, pleural line, and A-lines.

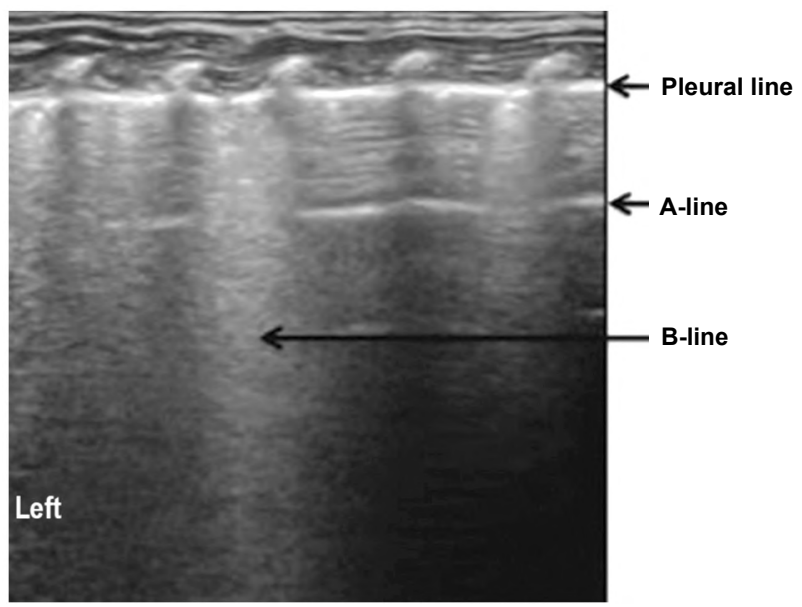

Fig. (2): B-lines project from the pleural line to the edge of the screen erase A-lines [11].

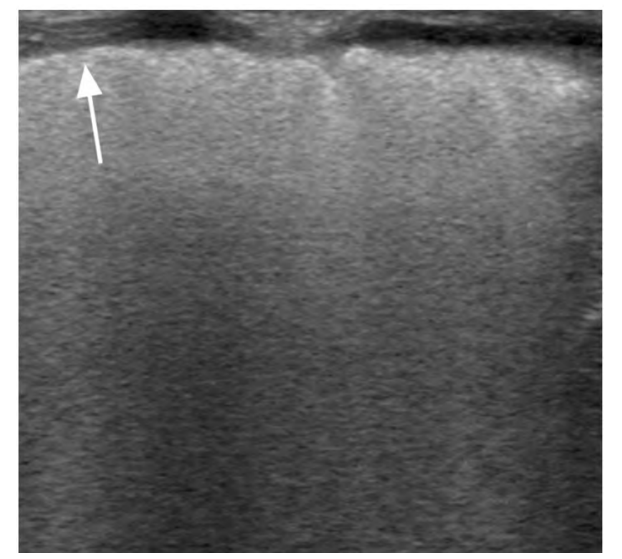

Fig. (3): LUS showing a diffuse and compact pattern of Blines [14].

\section{Results}

The study included 68 preterm neonates admitted in NICU presenting by respiratory distress. The gestational age ranged from 26 to 35 weeks (mean=30.24). The birth weight ranged from $800 \mathrm{gm}$ to $2.950 \mathrm{~kg}$ (mean=1.429kg). $41 / 68$ patients were males $(60.3 \%)$ and $27 / 68$ were females $(39.7 \%)$. $23 / 68(33.8 \%)$ were delivered vaginally while $45 / 68(66.2 \%)$ were delivered by cesarean section. 59 out of $68(86.8 \%)$ of the admitted patients presented with moderate respiratory distress and 9 out of $68(13.2 \%)$ presented with severe respiratory distress.

\section{1 st day of admission results:}

The stages of NRDS diagnosed by chest radiography at presentation are shown in (Table 2).

LUS within few hours of admission was able to diagnose RDS in $68 / 68$ patients $(100 \%)$, by demonstrating the three signs; absence of A-lines, bilateral compact B-lines and abnormal pleural line (thickened or blurred) Fig. (4).

Lung consolidation was seen in only $14 / 68$ (20.6\%) of the NRDS patients (Table 3).

Based upon these findings; 54 out of 68 (79.4\%) were diagnosed mild NRDS Fig. (5), while 14 out of $68(20.6 \%)$ were diagnosed as severe NRDS Fig. (6).

The degree of NRDS as diagnosed by LUS compared to CXR staging are shown in (Table 4).

Using lung consolidation in LUS as marker of severity and comparing it the CXR stage; all consolidations $(n=14 / 68)$ were always associated with stage III or IV NRDS by CXR and never seen with grade I or II RDS Fig. (7) (Table 5).

\section{Fifth day results:}

38 out of $68(55.9 \%)$ patients showed clear lung in both CXR and ultrasound with reappearance of the A-lines. 10 out of 68 (14.7\%) showed persistence of RDS in both CXR and LUS. 3/68 (4.4\%) were positive for RDS on CXR but not on LUS. 17 out of 68 (25\%) developed new opacities on CXR and had clinical and laboratory data consistent with either pneumonia or pulmonary hemorrhage. LUS scans detected new subpleural consolidations with air bronchogram in all those 17 cases. In our study, we could not differentiate between the origins of the consolidation stemming from pneumonia $(n=11 / 17)$ or pulmonary hemorrhage $(n=6 / 17)$. LUS in comparison to CXR as regard detection of persistence or clearance of RDS on 5th day had both specificity and PPV of $100 \%$ while sensitivity and NPV were $90 \%$ and $90.2 \%$ respectively.

Based on its LUS features; those consolidations are different from consolidations on day one where 
air bronchograms were absent and the size was smaller.

The follow-up of the 14 patients with lung consolidation on day one was; four cases developed pulmonary hemorrhage, one case developed pneumonia, two cases did not develop complications but showed persistence of RDS. The remaining seven cases did not develop complications and were negative for RDS in both modalities on day five.
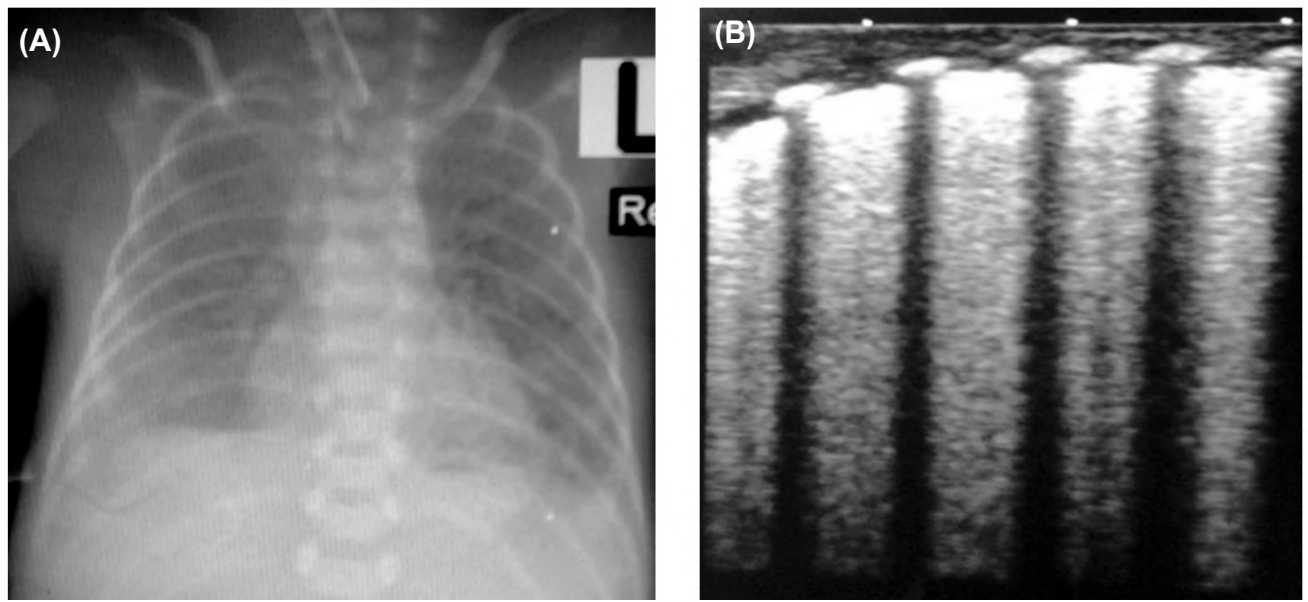

Fig. (4): CXR (A) showing bilateral alveolar opacities, stage II. LUS (B) shows absent A-lines, thick pleural line and B-lines.
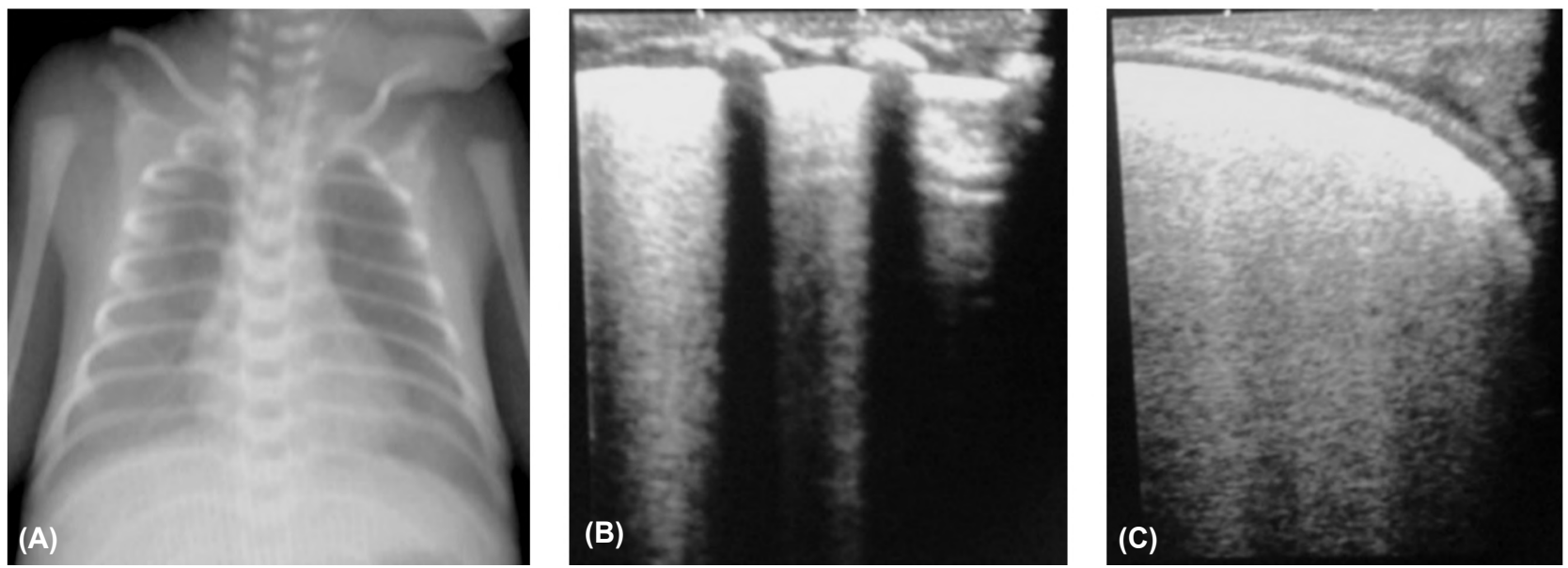

Fig. (5): Mild RDS. CXR (A) showing stage I RDS with diffuse granular pattern. LUS (B,C) shows thick pleural line and compact B-lines.
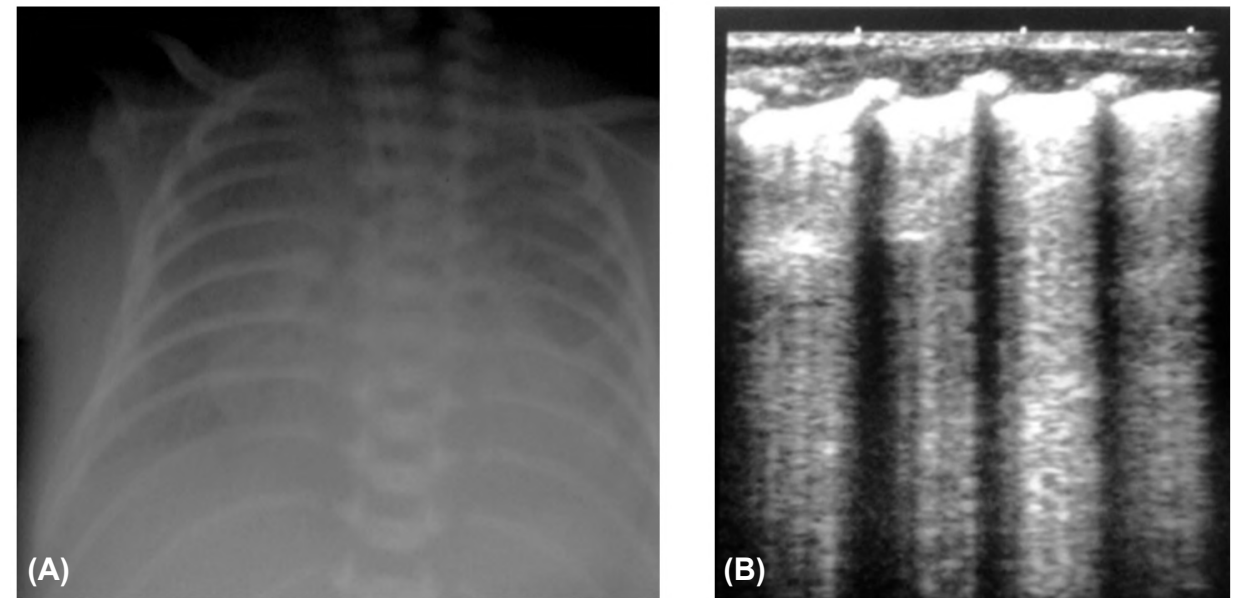

Fig. (6): Severe RDS. CXR (A) shows stage III with bilateral alveolar opacities. LUS (B) shows thick pleural line and B-lines. 

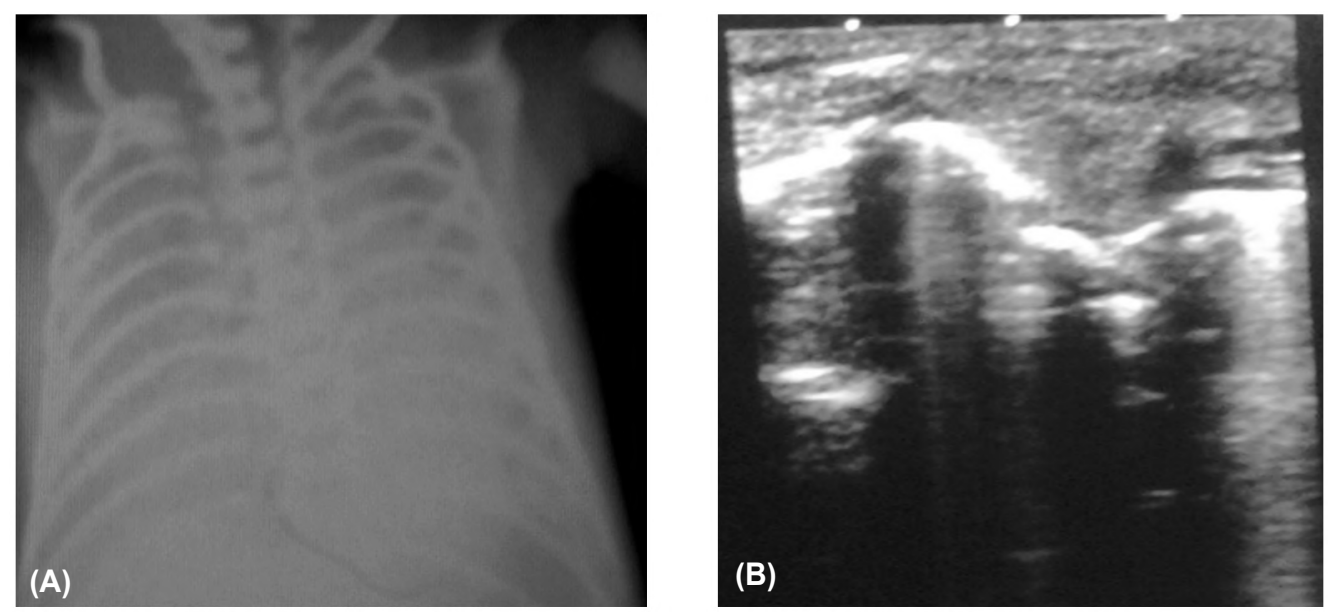

Fig. (7): Severe RDS. CXR (A) showing bilateral alveolar opacities obscuring cardiac borders, stage IV. LUS (B) showing subpleural consolidation with air bronchogram.

Table (2): Chest radiography stages at presentation.

\begin{tabular}{lll}
\hline Stage & No & $\%$ \\
\hline I & 1 & 1.5 \\
II & 15 & 22.1 \\
III & 24 & 35.3 \\
IV & 28 & 41.2 \\
\hline
\end{tabular}

Table (3): Lung ultrasound stages at presentation.

\begin{tabular}{lcc}
\hline Stages & No & $\%$ \\
\hline Mild (with 3 signs of RDS) & 54 & 79.4 \\
Sever (with 3 signs of RDS + lung consolidation) & 14 & 20.6 \\
\hline
\end{tabular}

Table (4): Degree of RDS in the 1 st day of life as diagnosed by CXR and LUS.

\begin{tabular}{|c|c|c|c|c|c|}
\hline & \multicolumn{4}{|c|}{ CXR on day one } & \multirow{3}{*}{ Total } \\
\hline & \multicolumn{2}{|c|}{ Severe } & \multicolumn{2}{|c|}{ Mild } & \\
\hline & III & IV & I & II & \\
\hline \multicolumn{6}{|l|}{ LUS on day one: } \\
\hline $\begin{array}{l}\text { - With } 3 \text { sign of RDS + lung } \\
\text { consolidation (severe). }\end{array}$ & 9 & 5 & 0 & 0 & 14 \\
\hline • With 3 sign of RDS (mild). & 15 & 23 & 1 & 15 & 54 \\
\hline Total & 24 & 28 & 1 & 15 & 68 \\
\hline
\end{tabular}

Table (5): Degree of RDS in the 1 st day of life as diagnosed by LUS and CXR using consolidation as a marker of severe RDS by LUS.

\begin{tabular}{lccc}
\hline & \multicolumn{2}{c}{ CXR } & \\
\cline { 2 - 3 } & $\begin{array}{c}\text { Severe RDS } \\
\text { (III, IV) }\end{array}$ & $\begin{array}{c}\text { Mild RDS } \\
\text { (I, II) }\end{array}$ & Total \\
\hline LUS: & 14 & 0 & 14 \\
$\quad$ Lung consolidation & 38 & 16 & 54 \\
$\quad$ Absent consolidation & 52 & 16 & 68 \\
\hline Total & & & \\
\hline
\end{tabular}

\section{Discussion}

Respiratory-Distress Syndrome (RDS) accounts for high neonatal mortality and morbidity occurring primarily in premature infants [16].

Chest X-ray being an essential tool in the diagnosis of pulmonary diseases in preterm and term neonates; is frequently carried out in Neonatal Intensive Care Units (NICU). Chest X-ray has been the standard imaging tool for diagnosing RDS [4] . CXR has also been used to monitor response to treatment increasing the risk for long-term adverse effects [17].

In recent years, LUS has been an emerging tool in the evaluation of many neonatal diseases including RDS. Lung ultrasound has many advantages being; nonionizing, low-cost, done bedside, easy to operate, and can be repeated several times without the hazards radiation exposure. As regarding diagnosing pulmonary disease, LUS has very high accuracy and reliability [6]

The current study was a prospective study to determine the efficacy of lung ultrasound in diagnosing NRDS and to monitor the response to therapy. In comparison with the CXR; LUS had sensitivity, specificity, PPV and NPV of $100 \%$ in diagnosing RDS.

The results of this study are in concordance with those of Copetti et al., [16] and Bober et al., [17]. The latter showed lesser specificity may be related to the fact that they used transabdominal approach, unlike our study where we only used the transthoracic approach. 
Our results are in agreement with Lichtenstein and Mauriat 2012 [12], who described the ultrasound findings for NRDS; pleural line abnormalities, absent A-lines, and bilateral compact B-lines. Lung consolidation correlated with stages III and IV NRDS by CXR.

In concordance with results of Sartori et al., [10], we also found that lung consolidation was found in severe NRDS (stages III and IV NRDS by CXR).

While Liu et al., [15], stated that the lung consolidation is the most important indicator of RDS, and it can be seen in all patients, however the extent of the consolidation correlates with the grade of RDS. In mild RDS (stage II), consolidation is usually focal and limited to the subpleural area with or without air bronchograms. Compared to severe RDS (stages III and IV), the area of consolidation is extended with obvious air bronchograms.

Consistent with study by Liu et al., [15], LUS was able to monitor response to therapy and suggest re-expansion of the lungs, based on the reappearance of the A-lines.

Our study showed LUS in comparison to CXR had both specificity and PPV of $100 \%$ while sensitivity and NPV were $90 \%$ and $90.2 \%$ respectively in following the response to treatment. These are in concordance with those of Hosam El-Deen et al., [18] and Pieper et al., [6] .

In our study, 17/68 (25\%) of cases developed pulmonary complications of NRDS during the course of the disease. They showed new opacities on CXR and had clinical and laboratory data consistent with either pneumonia or pulmonary hemorrhage. LUS scans detected new subpleural consolidations with air bronchogram in all those 17 cases with a positive predictive value of $100 \%$, which indicates the reliability of LUS findings. These results are in agreement with those of Jovan L., [19] and Smargiassi et al., [20]. The drawback in our study, we could not differentiate between pneumonia and hemorrhage.

While Volpicelli et al., [21] stated that although LUS is a clinically useful tool for the diagnosis of pneumonia, it does not rule out consolidations that do not reach the pleura.

\section{Conclusion:}

LUS is safe and non-invasive technique and can be used as diagnostic tool in the diagnosis of
RDS and following up the effect of treatment thus reducing number of carried out X-ray.

\section{References}

1- AGRONS G.A., COURTNEY S.E., STOCKER J.T., et al.: Lung disease in premature neonates: Radiologicpathologic correlation. Radiographics, 25, pp. 1047-73, 2005.

2- HILES M., CULPAN A.M., WATTS C., et al.: Neonatal respiratory distress syndrome: Chest X-ray or lung ultrasound? A systematic review. Ultrasound., May, 25 (2): 80-91, 2017.

3- FRANCESCO R., FIORELLA M., ANGELA S., et al.: Point-of care chest ultrasound in the Neonatal Intensive Care Unit. J. Pediatr. Neonatal Individual Med., 2 (2): e020214, 2013.

4- MAZRANI W., McHUGH K. and MARSDEN P.J.: The radiation burden of radiological investigations. Arch. Dis. Child, 92:1127-3 1, 2007.

5- KULKARNI, MEHTA N. and JADHAV V.: Chest sonography images in neonatal R.D.S. and proposed grading. iosrphr.org, Volume 5, Issue 11: PP. 29-31, 2015.

6- PIEPER C.H., SMITH J. and BRAND E.J.: The value of ultrasound examination of the lungs in predicting bronchopulmonary dysplasia. Pediatr. Radiol., 34: 227-31, 2004.

7- SARTORI S. and TOMBESI P.: Emerging roles for transthoracic ultrasonography in pulmonary disease. World J. Radiol., Jun. 28, 2 (6): 203-14, 2010.

8- HANSEN T. and CORBET A.: Disorders of the transition. In: Taeusch WH, Ballard RA, Avery ME, editors. Diseases of the newborn. Philadelphia: W.B. Saunders Company; p. 498-504, 1991.

9- MATHIS G.: Thoraxsonography. I. Chest wall and pleura. Ultrasound Med. Biol., 23: 1131-9, 1997.

10- LICHTENSTEIN D., MEZIÉRE G., BIDERMAN P., et al.: The comettail artifact: An ultrasound sign ruling out pneumothorax. Intensive Care Med., 25: 383-8, 1999.

11-SHUI WEN CHEN, MING YU ZHANG, et al.: Application of Lung. Ultrasonography in the Diagnosis of Childhood Lung Diseases. Chinese Medical Journal, 128: Issue 19, 2015.

12- LICHTENSTEIN and MAURIAT: Lung Ultrasound in the Critically Ill Neonate. Current Pediatric Reviews, 8: 217-23, 2012.

13- LICHTENSTEIN D., MEZIÉRE G., BIDERMAN P., et al.: The comet-tail artifact. An ultrasound sign of alveolarinterstitial syndrome. Am. J. Respir. Crit. Care Med., 156: 1640-6, 1997.

14- J. RODRÍGUEZ-FANJUL, ESPONERA C.B., HERNANDO J.M., et al.: Lung ultrasound as a tool to guide the administration of surfactant in premature neonates. An. Pediatr. (Barc), 84: 249-53-Vol. 84, 2016.

15- LIU J., CAO H.Y., WANG H.W., et al.: The role of lung ultrasound in diagnosis of respiratory distress syndrome in newborn infants. Iran J. Pediatr., 24: 147-54, 2014. 
16- COPETTI R., CATTAROSSI L., MACAGNO F., et al.: Lung ultrasound in respiratory distress syndrome: A useful tool for early diagnosis. Neonatology, 94: 52-9, 2008.

17- BOBER K. and SWIETLINSKI J.: Diagnostic utility of ultrasonography for respiratory distress syndrome in neonates. Med. Sci. Monit., 12: CR440-CR446, 2006.

18- HOSAM EL-DEEN GALAL M. EL-MALAH A., SEIF HANY, et al.: Lung ultrasonography in evaluation of neonatal respiratory distress syndrome. The Egyptian Journal of Radiology and Nuclear Medicine, 46: 469-74, 2015.

19- JOVAN L.: Lung ultrasonography of pulmonary compli- cations in preterm infants with respiratory distress syndrome Upsala Journal of Medical Sciences, 117: 10-17, 2012.

20- SMARGIASSI1, INCHINGOLO1, GINO SOLDATI, et al.: The role of chest ultrasonography in the management of respiratory diseases: document II. Multidisciplinary Respiratory Medicine, 8: 55, 2013.

21- VOLPICELLI G., ELBARBARY M., BLAIVAS M., et al.: International Liaison Committee on Lung Ultrasound (ILC-LUS) for the International Consensus Conference on Lung Ultrasound (ICC-LUS): International evidencebased recommendations for point-of-care lung ultrasound. Intensive Care Med., 38 (4): 577-91, 2012.

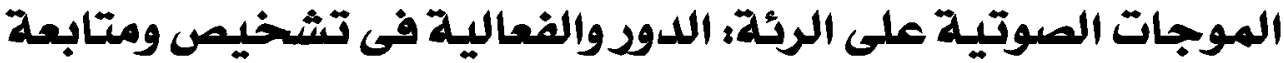

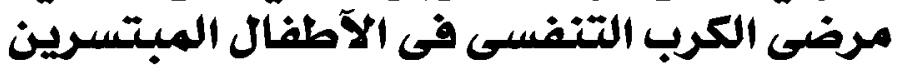

\author{
الهدف: تقييم فعالية الموجات الصوتية على الرئة فى تثخيص ومتابعة مرض الكرب التنفسى فى حديثى الولادة المبكرة.

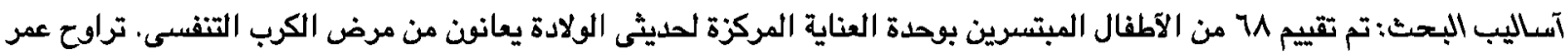

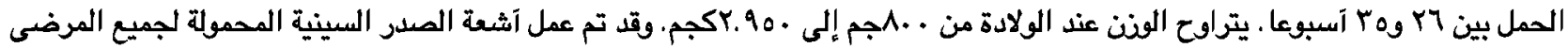

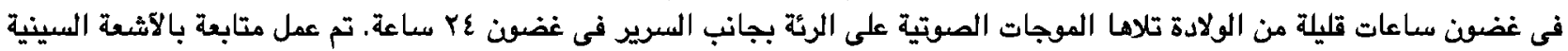

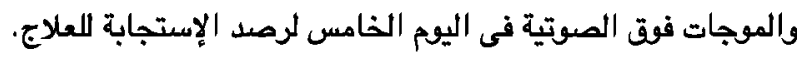

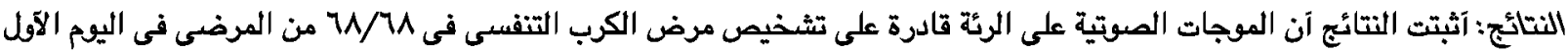

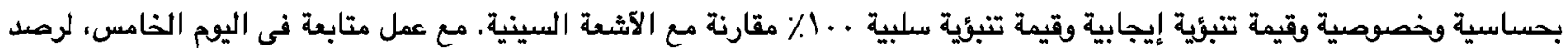

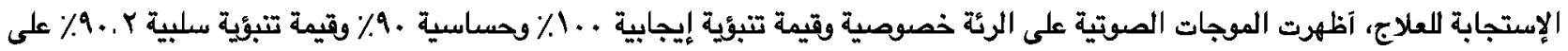 \\ التوالى مقارنة بالآثـعة السينية.

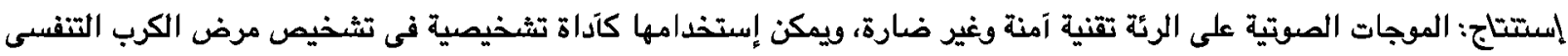 \\ ومتابعة تآثير العلاج وبالتالى الحد من عمل الآثيعة السينية.
}

